\title{
Current range of Agrilus planipennis Fairmaire, an alien pest of ash trees, in European Russia and Ukraine
}

\author{
Marina J. Orlova-Bienkowskaja ${ }^{1}$ (D) - Alexander N. Drogvalenko ${ }^{2} \cdot$ Ilya A. Zabaluev ${ }^{1}$ - Alexey S. Sazhnev ${ }^{3}$. \\ Elena Y. Peregudova ${ }^{4}$. Sergey G. Mazurov ${ }^{5}$. Evgenij V. Komarov ${ }^{6}$. Vitalij V. Struchaev ${ }^{7}$. Vladimir V. Martynov ${ }^{8}$. \\ Tatyana V. Nikulina ${ }^{8} \cdot$ Andrzej O. Bieńkowski $^{1}$
}

Received: 23 October 2019 / Accepted: 4 February 2020 / Published online: 23 March 2020

(C) INRAE and Springer-Verlag France SAS, part of Springer Nature 2020

\begin{abstract}
- Key message The emerald ash borer (Agrilus planipennis Fairmaire), an alien pest native to Asia, has spread to Ukraine and 16 regions of European Russia. It severely damages Fraxinus pennsylvanica Marsh. introduced from North America, but serious damage to European ash (Fraxinus excelsior L.) has not been detected in forests.

- Context The first detection of A. planipennis in European Russia was in Moscow in 2003, when it began to spread.

- Aims To determine the range of A. planipennis as of 2020.

- Methods In 2017-2020, our Russian-Ukrainian research team examined $>7000$ F. pennsylvanica trees and $>2500$ F. excelsior trees in 84 localities of European Russia, Ukraine, and Belarus.

- Results The current range exceeds the area of Spain and includes the Luhansk region of Ukraine and 16 regions of ER: Belgorod, Bryansk, Kaluga, Kursk, Lipetsk, Moscow, Orel, Ryazan, Smolensk, Tambov, Tula, Tver, Vladimir, Volgograd, Voronezh, and Yaroslavl. Agrilus planipennis was not detected in Belarus. The overwhelming majority of the infestations were found on $F$. pennsylvanica. All known cases of infestation of the native species $(F$. excelsior) are from artificial plantings.

- Conclusion Agrilus planipennis will appear in other European countries soon and damage F. pennsylvanica. Further surveys are necessary to determine whether $A$. planipennis infests $F$. excelsior in forests.
\end{abstract}

Handling Editor: Aurélien Sallé

Contributions of the co-authors Conceptualization: M.O.B.; Investigation: M.O.B., A.D., I.Z., A.S., E.P., S.M., E.K., V.S., V.M., T.N., A.B.; Writing — original draft: M.O.B., A.B.; Writing - review and editing: M.O.B., A.B.; Funding acquisition: M.O.B.

This article is part of the topical collection on Entomological issues during forest diebacks.

Reference to pre-print servers The Preprint version of this article is available in the BioRxiv server, https://doi.org/10.1101/689240

Marina J. Orlova-Bienkowskaja

marinaorlben@yandex.ru

Alexander N. Drogvalenko

triplaxxx@ukr.net

Ilya A. Zabaluev

fatsiccor66@mail.ru

Alexey S. Sazhnev

sazh@list.ru

Elena Y. Peregudova

dinamo-1@mail.ru

Sergey G. Mazurov

mazusergej@yandex.ru

\author{
Evgenij V. Komarov \\ evkomarov@rambler.ru \\ Vitalij V. Struchaev \\ vivastru@mail.ru \\ Vladimir V. Martynov \\ martynov.scarab@yandex.ua \\ Tatyana V. Nikulina \\ nikulinatanya@mail.ru \\ Andrzej O. Bieńkowski \\ bienkowski@yandex.ru
}

Extended author information available on the last page of the article 
Keywords Emerald ash borer $\cdot$ EAB $\cdot$ Fraxinus pennsylvanica $\cdot$ Fraxinus excelsior $\cdot$ Invasive pest $\cdot$ Ash

\section{Introduction}

The emerald ash borer, Agrilus planipennis Fairmaire (Coleoptera: Buprestidae), is a devastating alien pest of ash trees in European Russia and North America (Baranchikov et al. 2008; Herms and McCullough 2014; Haack et al. 2015). It is included in the list of 20 priority quarantine pests of the EU (EU 2019). The native range of this wood-boring beetle occupies a restricted territory in East Asia (OrlovaBienkowskaja and Volkovitsh 2018). In 2003, A. planipennis was first recorded in European Russia, namely, in Moscow, and a severe outbreak and quick spread of the pest began (Baranchikov et al. 2008; Haack et al. 2015). By 2013, the pest was recorded in 9 regions of European Russia: from Yaroslavl in the north to Voronezh in the south (Straw et al. 2013; Orlova-Bienkowskaja 2014a). A probabilistic model of spread made in 2017 showed that in the next few years, the range of A. planipennis in Europe could expand significantly, and the pest could appear in neighboring countries (OrlovaBienkowskaja and Bieńkowski 2018a).

Fraxinus pennsylvanica Marsh. was introduced from North America and is widely planted in European Russia as an ornamental and landscape tree. It is highly susceptible to A. planipennis both in North America and Russia (Herms and McCullough 2014; Baranchikov et al. 2014). The overwhelming majority of detected infestations of ash trees in European Russia correspond to this North American ash species (Baranchikov et al. 2008; Straw et al. 2013; OrlovaBienkowskaja 2014a, etc.).

The only native ash species in European Russia is F. excelsior L. It is susceptible to the pest (Baranchikov et al. 2014). However, it is still unknown whether it is highly susceptible (as are the ash species native to North America) or less susceptible (as are the ash species native to Asia). On the one hand, the only cultivar of $F$. excelsior tested in a naturally infested experiment in America, cv. Aureafolia, had similar long-term mortality as that of F. nigra and F. pennsylvanica (Herms 2015). On the other hand, current experiments have shown that saplings of $F$. excelsior are much less susceptible than $F$. nigra Marsh. to A. planipennis (Showalter et al. 2019). Fraxinus excelsior is rare in the Moscow region and other regions of northern and central Russia. Therefore, information about the infestation of $F$. excelsior by A. planipennis is scarce and refers only to urban plantings and artificial shelterbelts, where $F$. excelsior is planted together with $F$. pennsylvanica (Straw et al. 2013; Baranchikov 2018). There is no information about the impact of $A$. planipennis on $F$. excelsior in natural forests.
Therefore, there is a great deal of uncertainty surrounding the likely future impact of $A$. planipennis on ash in European forests (Straw et al. 2013).

The main aim of our study was to determine the range of A. planipennis in Europe as of 2020. An additional aim was to obtain information about the current condition of $F$. excelsior in natural forest stands in some regions occupied by A. planipennis.

\section{Material and methods}

\subsection{Collation of previous records of $A$. planipennis}

We have studied the A. planipennis range in European Russia since 2013 and have carefully examined all records that have appeared in journal articles, conference papers, official quarantine documents, and other sources. These records, which comprise all of the published data on localities where A. planipennis has been detected, are compiled in Table 1 .

\subsection{Localities of the survey}

In 2017, 2018, and 2019, we examined more than 7000 green ash trees (F. pennsylvanica) and more than 2500 European ash trees $(F$. excelsior) in 84 localities of European Russia, Belarus, and Ukraine (Table 2, Figs. 1, 2).

1. We examined ash trees in 7 Russian cities, where A. planipennis was found 4-16 years ago. The aim was to determine whether ash trees and populations of A. planipennis still existed there.

2. We examined ash trees in localities where A. planipennis had not been reported before. The aim was to determine the current range of the pest in Europe. We selected particular survey areas so that they were situated in all directions from the previously known range of A. planipennis in Europe. If we found the pest outside the previously known range, we conducted the next survey in a locality situated further in the same direction. We repeated this procedure until we found localities without the pest. This protocol was flexible since we used all possibilities to examine as many localities as possible.

3. We examined more than $500 \mathrm{~F}$. excelsior in two localities in a large natural forest, Tulskie Zaseki, situated in the center of the current range of A. planipennis in European Russia. The aim was to determine whether there were trees infested with A. planipennis in this forest. 


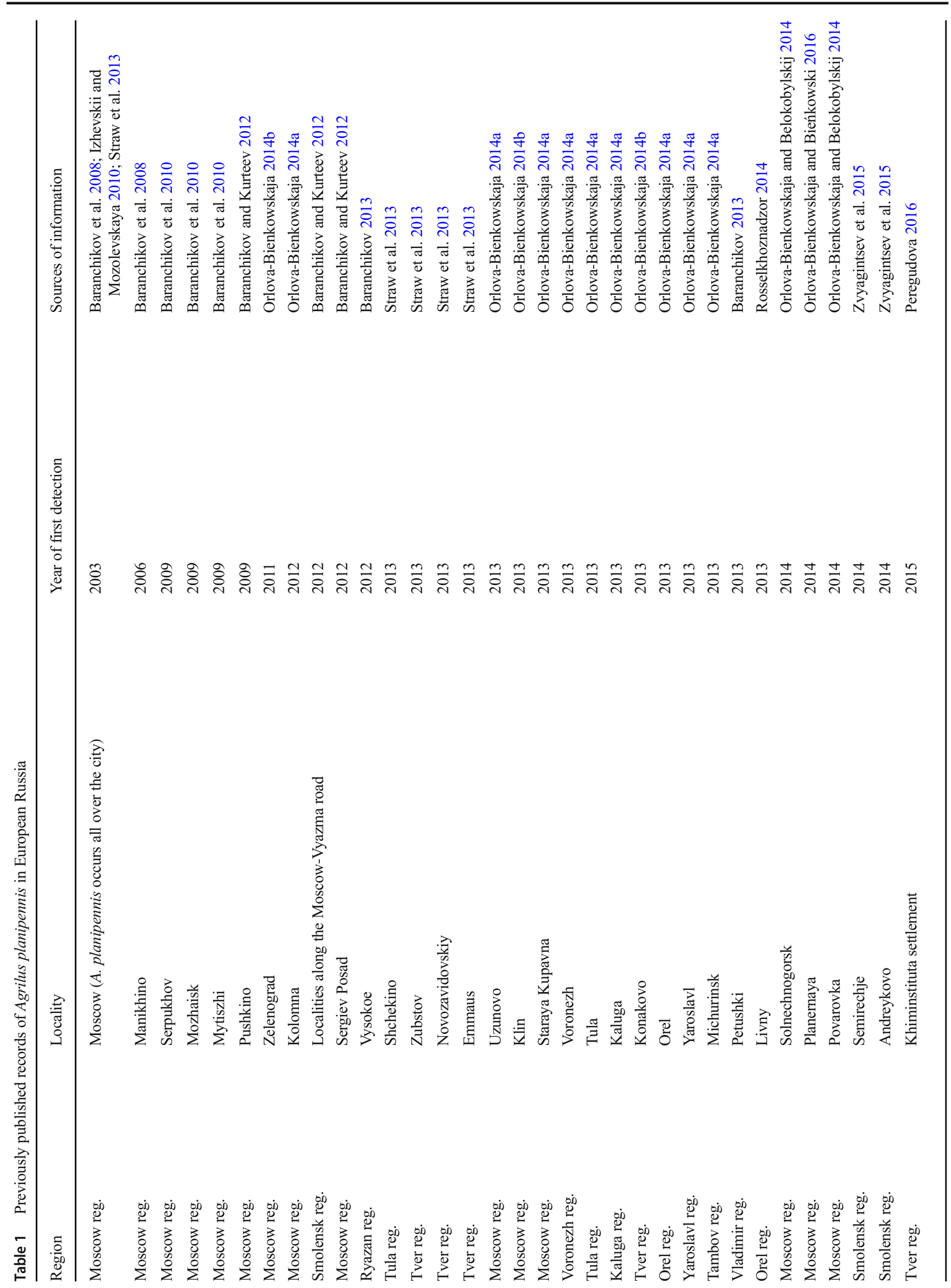




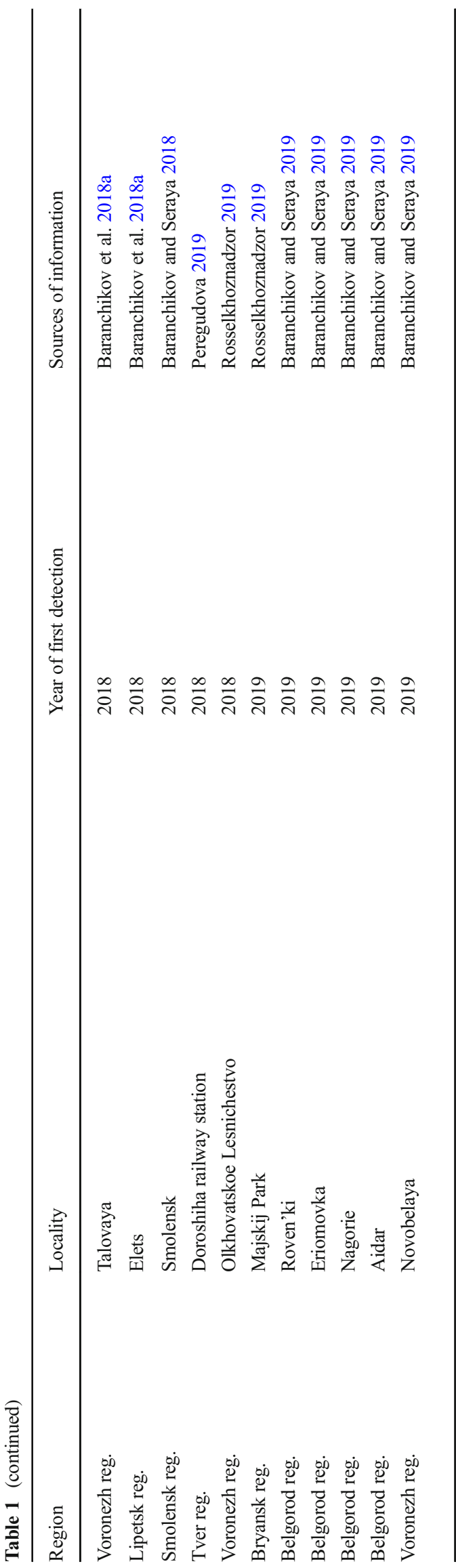

\subsection{Method of survey}

The survey of ash trees in each city always started from the main railway station. Usually, we stayed 1 day in each city and examined as many ash trees as we could. In most localities, we examined artificial plantings in cities, along motorways and railroads, and in shelterbelts. The survey of $500 \mathrm{~F}$. excelsior trees in the large Tulskie Zaseki Forest was conducted in two localities situated $25 \mathrm{~km}$ apart (see Table 2).

We used the standard method of A. planipennis detection used by many authors (Baranchikov and Kurteev 2012; Straw et al. 2013, etc.). We looked for ash trees with symptoms of general decline (dieback of the upper part of the stem, reduced foliage, epicormic shoots, loose bark, etc.) (Fig. 3) and examined the lower part of the stem, below $2 \mathrm{~m}$, for the presence of D-shaped exit holes of A. planipennis on the bark surface and larval galleries under the bark in the cambial region at the inner bark-sapwood interface (Figs. 4, 5). If we found exit holes and larval galleries, we took photos and tried to collect larvae from under the bark and adults (live specimens on leaves or dead specimens in their exit holes). The larvae and adults were examined in the laboratory to confirm their identification and deposited in the authors' collections. The following guides were used for identification: Chamorro et al. (2012) and Volkovitsh et al. (2019). The map was made with the ArcView GIS 10.4.1 (Esri) in A.N. Severtsov Institute of Ecology an Evolution, Russian Academy of Sciences, Moscow (Esri Customer Number 282718).

\section{Results}

\subsection{European Russia}

\subsubsection{Localities with previous detections of $A$. planipennis}

In 2019, we examined ash trees in 7 cities where A. planipennis was found 4-16 years ago: Moscow (first record in 2003), Kolomna (first record in 2012), Zelenograd (first record in 2011), Vyazma (first record in 2012), Tula (first record in 2013), Tver (first record in 2015), and Zubtsov (first record in 2013) (see Table 1 for information about the first records). The overwhelming majority of ash trees in these localities were $F$. pennsylvanica, which is one of the most common trees planted in the cities of European Russia. Fraxinus excelsior also occurred sometimes but much more rarely. In all these localities, ash trees were still common, and populations of A. planipennis still existed. Larvae or adults were found in all these localities in 2019.

Moscow was the entry point of invasion of A. planipennis in European Russia. By 2013, most ash trees in the city were heavily damaged (Orlova-Bienkowskaja 2014b), and some experts believed that ash trees would disappear throughout 


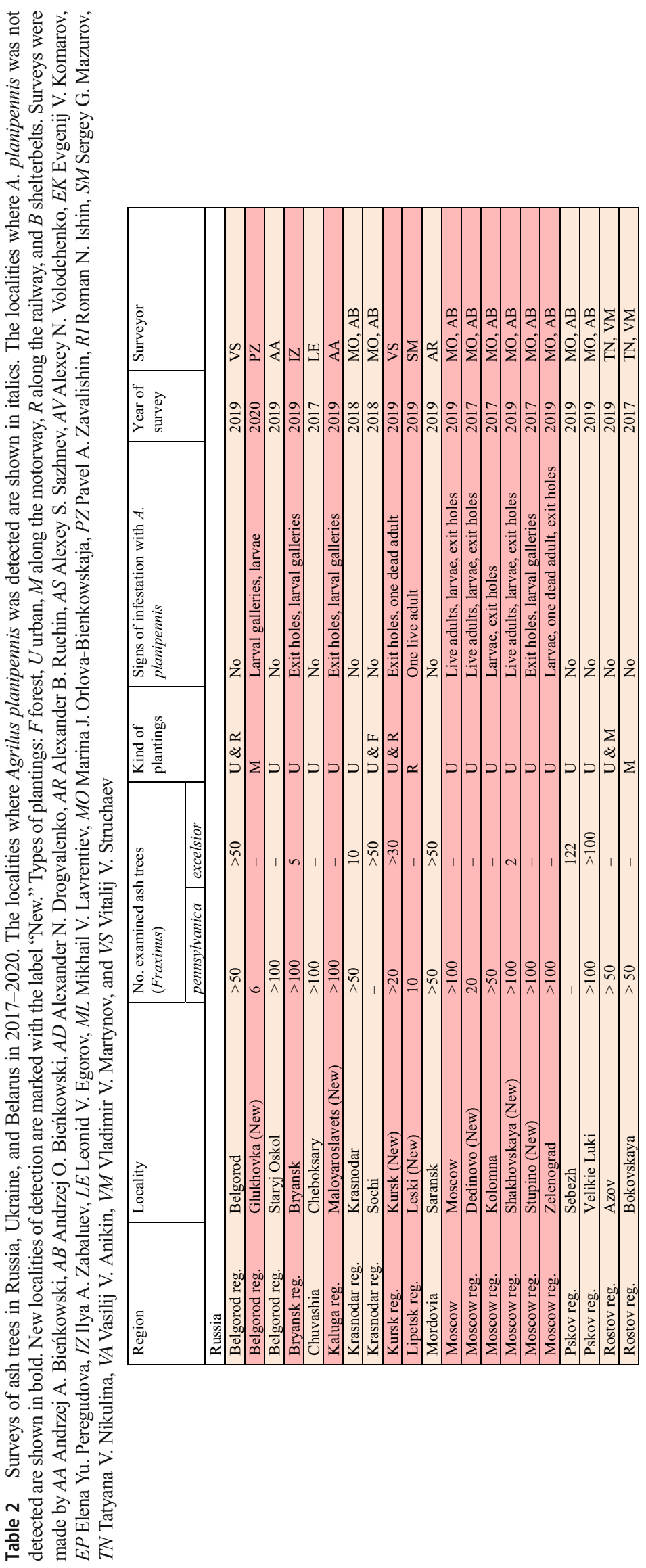

INRAC $\underline{\text { Springer }}$ 


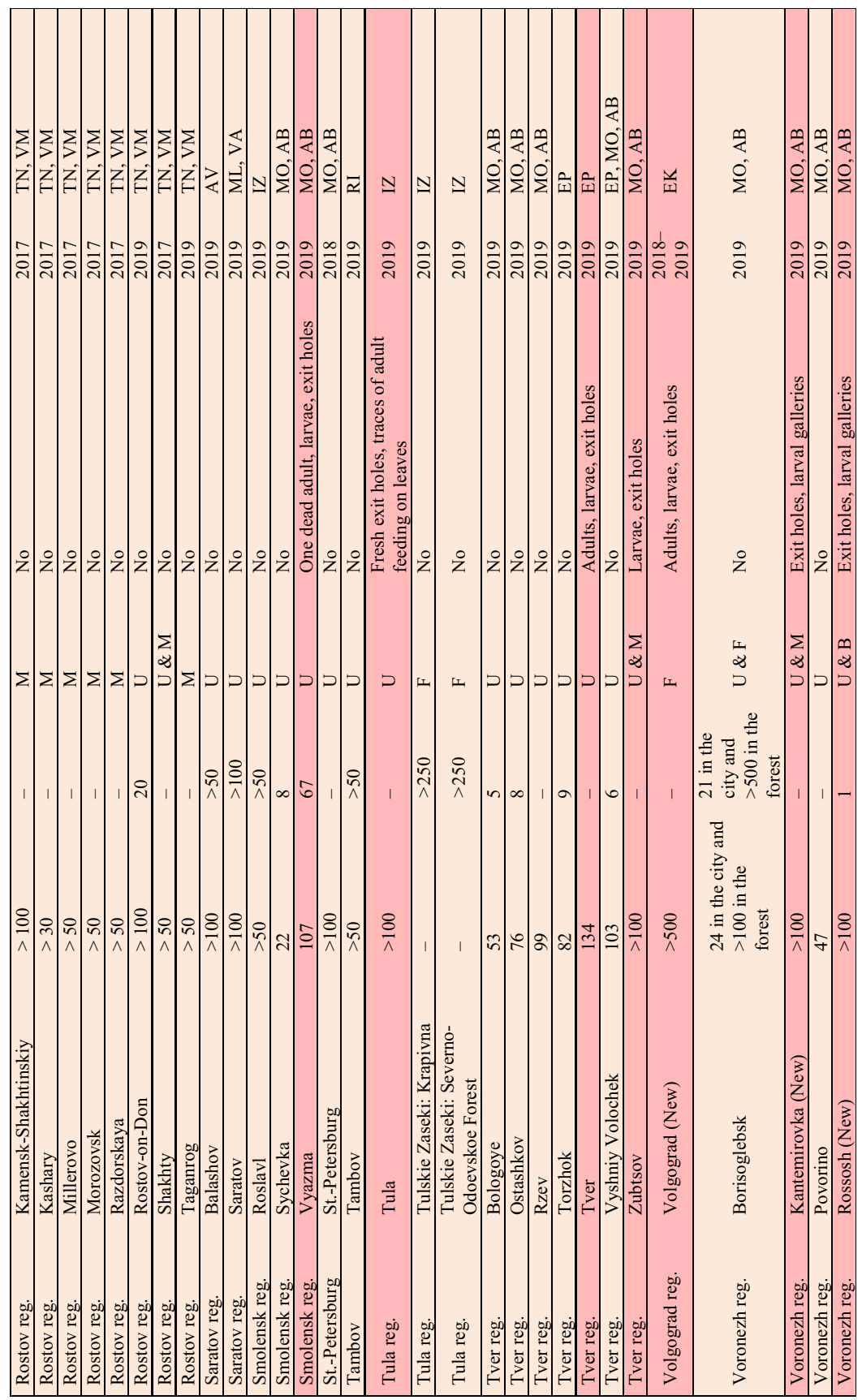

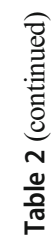




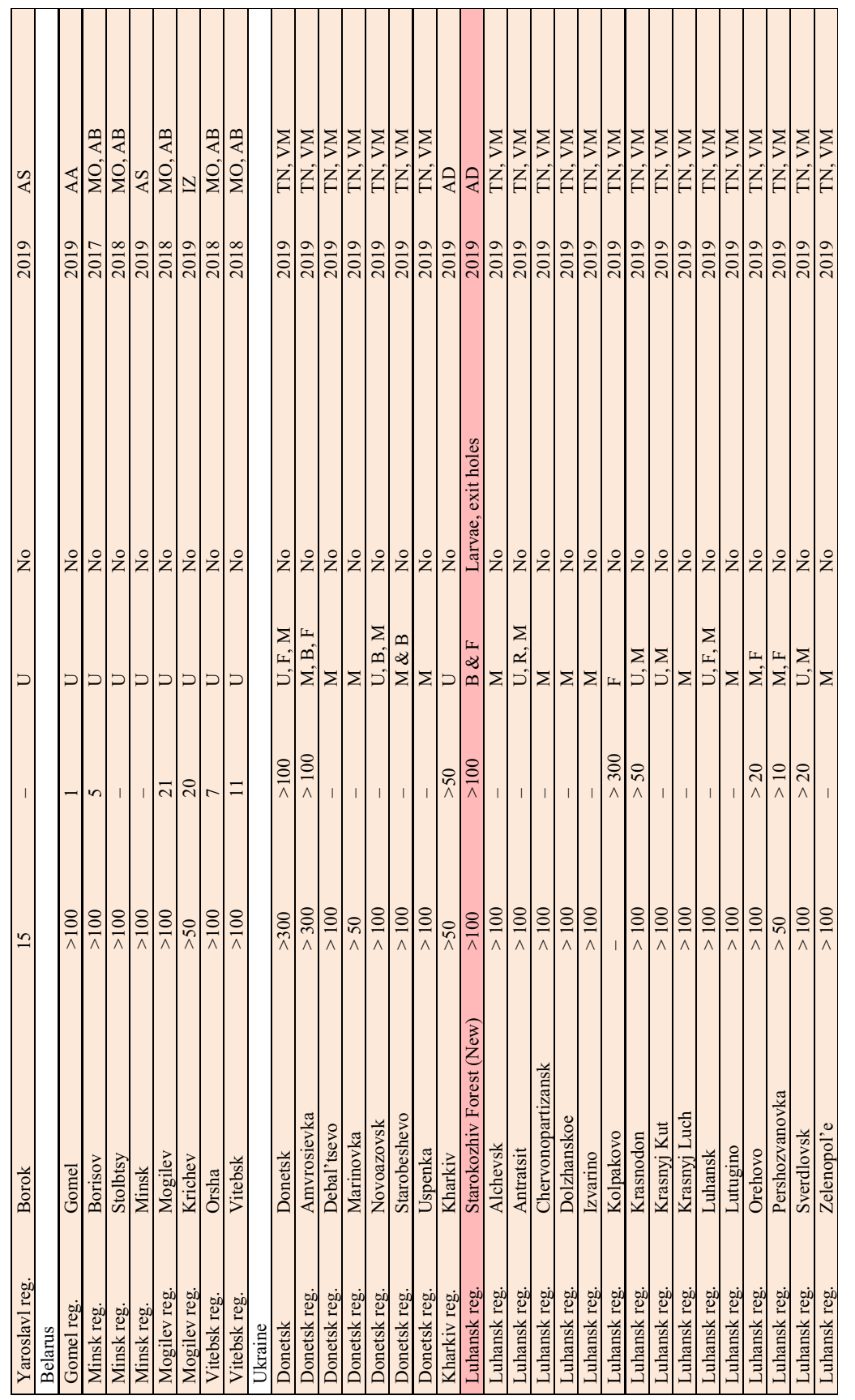

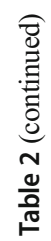




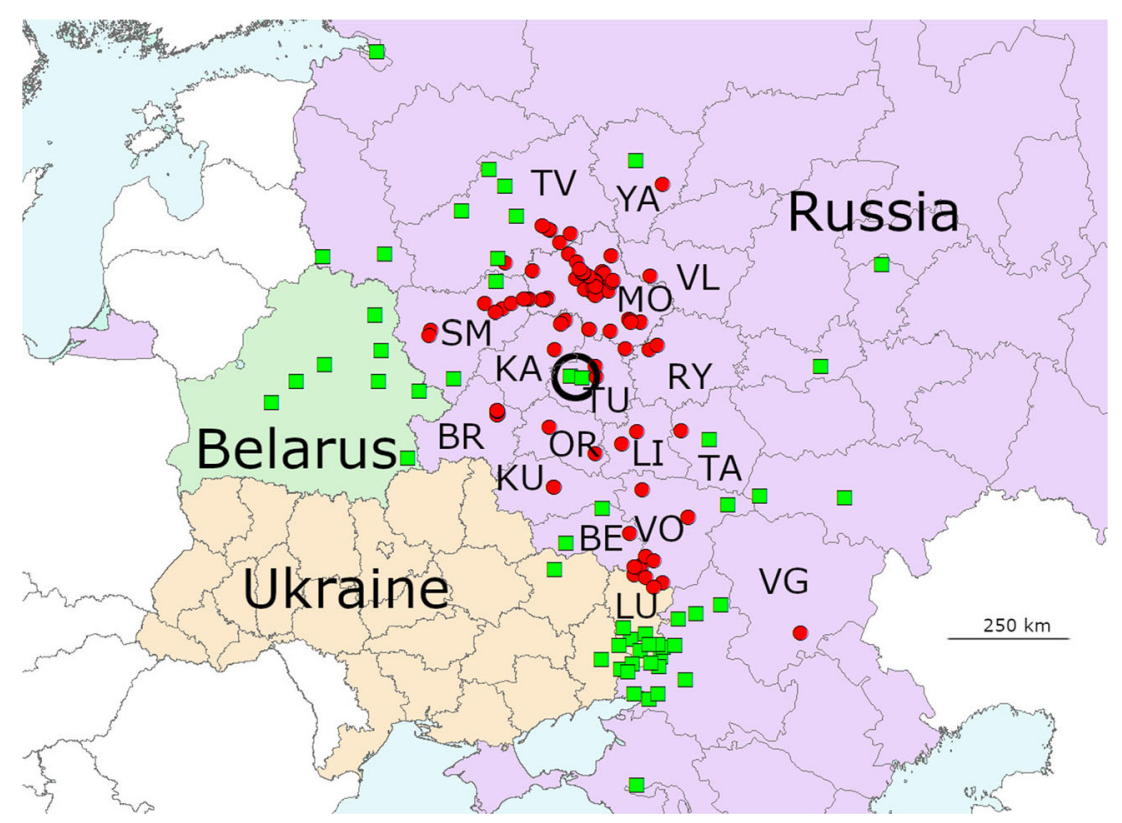

Fig. 1 Range of Agrilus planipennis in European Russia (R) and Ukraine (U) in 2020. The red dots indicate the localities where A. planipennis was detected. The green squares indicate the localities where it was not detected during surveys in 2017-2019. The black circle indicates the localities of the surveys of Fraxinus excelsior in the broad-leaved Tulskie Zaseki Forest. BR Bryansk region (R), BE Belgorod (R), KA
Kaluga region (R), LI Lipetsk region (R), LU Luhansk region (U), MO Moscow region (R), OR Orel region (R), RY Ryazan region (R), SM Smolensk region (R), TA Tambov region (R), TU Tula region (R), TV Tver region (R), VG Volgograd region (R), VL Vladimir region (R), VO Voronezh region $(\mathrm{R})$, and YA Yaroslavl region (R). The sources are shown in Tables 1 and 2 the city (Mozolevskaya 2012). However, surveys in 18 districts of Moscow in 2016 and 2017 showed that $F$. pennsylvanica was still common in the city, and A. planipennis had become rare (Orlova-Bienkowskaja and Bieńkowski 2018b). The survey in 2018 and 2019 confirmed this result. The reason for the decline in A. planipennis

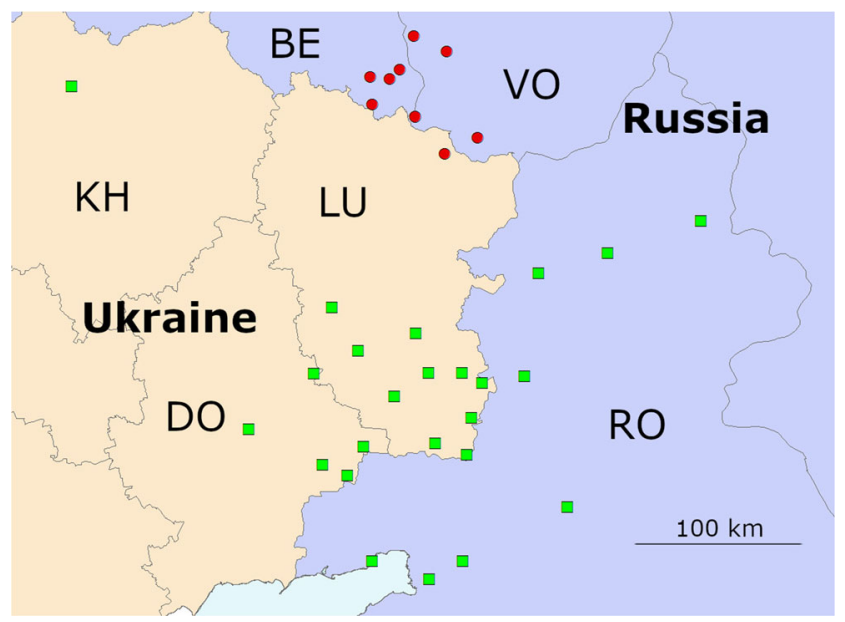

Fig. 2 Results of the surveys in the eastern part of Ukraine (U) and the neighboring regions of Russia (R). The red dots indicate the localities where we detected A. planipennis in 2017-2019. The green squares indicate the localities where A. planipennis was not detected during surveys in 2017-2019. BE Belgorod region (R), DO Donetsk region (U), KH Kharkiv region (U), LU Luhansk region (U), RO Rostov region $(\mathrm{R})$, and $\mathrm{VO}$ Voronezh region $(\mathrm{R})$ population in Moscow is unknown. It could be the result of mortality caused by the European parasitoid of A. planipennis Spathius polonicus Niezabitowski, 1910 (Hymenoptera: Braconidae: Doryctinae) (Orlova-Bienkowskaja and Belokobylskij 2014).

Infestations were found in all cities of the Moscow region surveyed by us in 2017-2019 (Table 2). In particular, a severe outbreak was recorded in 2019 in the city of Shakhovskaya. Almost all ash trees in the city were heavily infested. On 16 July 2019, more than 100 A. planipennis adults and larvae were collected there.

\subsubsection{Western regions: Tver, Pskov, Smolensk regions, and St. Petersburg}

We tried to find A. planipennis in 10 new localities of European Russia situated west and northwest of the border of the previously known range as of 2016: the Pskov region (Sebezh and Velikie Luki), Smolensk region (Roslavl and Sychevka), Tver region (Bologoye, Ostashkov, Rzev, Torzhok, and Vyshniy Volochek) and St. Petersburg. However, we detected no signs of the infestation with A. planipennis in these localities. It is interesting that we failed to find A. planipennis even in the city of Rhev, which is only $15 \mathrm{~km}$ northwest of Zubtsov, where an outbreak of A. planipennis was detected in 2013 (Straw et al. 2013) and is still continuing (based on our observations in 2019). 


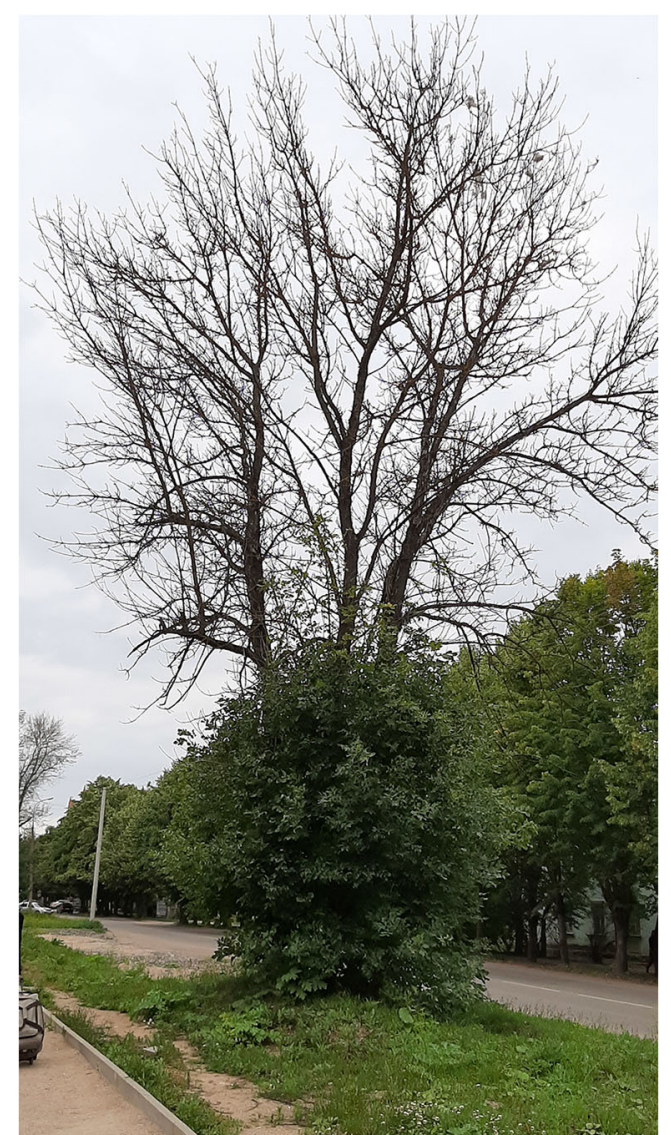

Fig. 3 Fraxinus pennsylvanica tree heavily damaged by Agrilus planipennis in Vyazma, Russia, in June 2019. Symptoms of general decline: dieback of the upper part of the stem and epicormic shoots. Photo by M.J. Orlova-Bienkowskaja

\subsubsection{Volgograd region}

In a planting of declining $F$. pennsylvanica trees (105 ha) on Sarpinsky Island in the Volga River (near the city of Volgograd) in October 2018, the trees were severely damaged by $A$. planipennis. The island is occupied by a floodplain forest, initially consisting of Quercus, Populus, and Ulmus trees, which was later replaced by an adventive plant: $F$. pennsylvanica. In different parts of the island, the infestation of ash trees varied from $20-30 \%$ to $90-100 \%$. The decline in the ash plantings because of $A$. planipennis outbreak attracted the attention of the local television company (Vesti Volgograd 2018). In 2019, infested trees were also detected on the left bank of the Volga River, in the Volga-Akhtuba floodplain, on the Sarepta Peninsula and in the center of Volgograd city (Mira Street).

\subsubsection{Kursk region}

In 2014, we surveyed more than $100 \mathrm{~F}$. pennsylvanica trees in Kursk city near the main railway station and did not find evidence of $A$. planipennis (Orlova-Bienkowskaja and
Bieńkowski, unpublished data). In 2016, the survey in Kursk was repeated by an expert from the All-Russian Center of Plant Quarantine, Y.N. Kovalenko, and he also did not find A. planipennis (unpublished data). In 2019, we examined more than $100 \mathrm{~F}$. pennsylvanica trees in plantings along the railway near the main railway station in Kursk and found that at least half of the trees had A. planipennis exit holes. One dead adult specimen was collected in its exit hole. Additional examinations of $F$. pennsylvanica trees in the parks of Boeva Dacha and Pyatidesyatiletiya VLKSM showed that many trees were in poor condition and had A. planipennis exit holes.

\subsubsection{Lipetsk region}

The Lipetsk region is surrounded by the Tula, Orel, Ryazan, Voronezh, and Tambov regions, where A. planipennis was found in 2013 (Orlova-Bienkowskaja 2014a), but M.J. Orlova-Bienkowskaja did not find any trees infested with A. planipennis in the city of Gryazy in the Lipetsk region in 2013. However, many $F$. pennsylvanica trees were in poor condition, and the species Agrilus convexicollis Redtenbacher, which is often associated with A. planipennis, was found (OrlovaBienkowskaja and Volkovitsh 2014). In 2018, A. planipennis was first found in the Lipetsk region in the city of Elets (Baranchikov 2018). On 22 June 2019, we collected one adult $A$. planipennis approximately $40 \mathrm{~km}$ from Elets in plantings of $F$. pennsylvanica along the railway in Leski, Lipetsk region. Examination of 10 trees in this planting did not reveal exit holes, but all the trees of A. planipenis were in poor condition and had dieback in the upper canopy.

\subsubsection{Voronezh region}

Agrilus planipennis was first detected in the Voronezh region in 2013 in the city of Voronezh (OrlovaBienkowskaja 2014a). In 2018, it was detected in other localities: in the very south of the region $\left(50^{\circ} 12^{\prime} \mathrm{N}\right.$, exact location is not known) and in the city of Talovaya (Baranchikov et al. 2018a), as well as in Olkhovatskoe Lesnichestvo (Rosselkhoznadzor 2019). In 2019, we surveyed ash trees in four other localities of the Voronezh region. Agrilus planipennis was not found in the northeast of the region (Borisoglebsk and Povorino), but was found in the following areas in the center and south of the region:

1. Rossosh. More than 100 heavily infested $F$. pennsylvanica trees with larval galleries and exit holes were found in a shelterbelt around the Chkalovskij district (50.201158 N, $39.604695 \mathrm{E}$ ). One $F$. pennsylvanica and one $F$. excelsior 
Fig. 4 Adults of A. planipennis and their exit holes. a Adults of Agrilus planipennis in pupal cells on Fraxinus pennsylvanica in Volgograd, Russia, in 2018. Photo by E.V. Komarov. b Exit hole of Agrilus planipennis on Fraxinus pennsylvanica in Volgograd, Russia, in 2018. Photo by E.V. Komarov. c Dead adult Agrilus planipennis found in Kursk in its exit hole on Fraxinus pennsylvanica in July 2019. Photo by V.V. Struchaev. d Adult of Agrilus planipennis on a leaf of Fraxinus pennsylvanica in Volgograd, Russia in 2018. Photo by E.V. Komarov

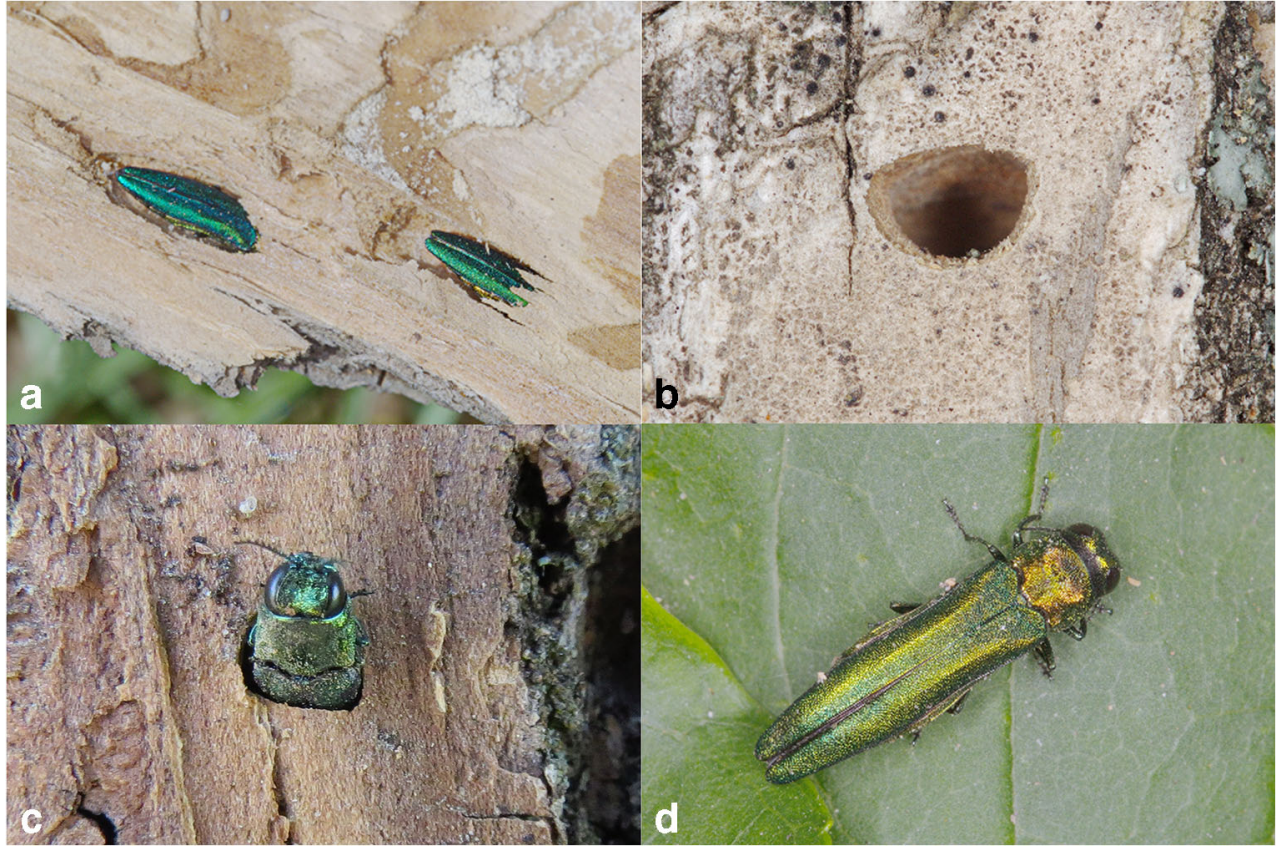

with exit holes and larval galleries were found near the main railway station $(50.184266 \mathrm{~N}, 39.600577 \mathrm{E})$.

2. Kantemirovka. One F. pennsylvanica with A. planipennis exit holes and larval galleries was found in the territory of the House of Culture (49.698968 N, 39.860308 E). Trees of $F$. pennsylvanica with A. planipennis exit holes and larval galleries were also found near a gas station on the R-194 road (49.758194 N, $39.843341 \mathrm{E})$.

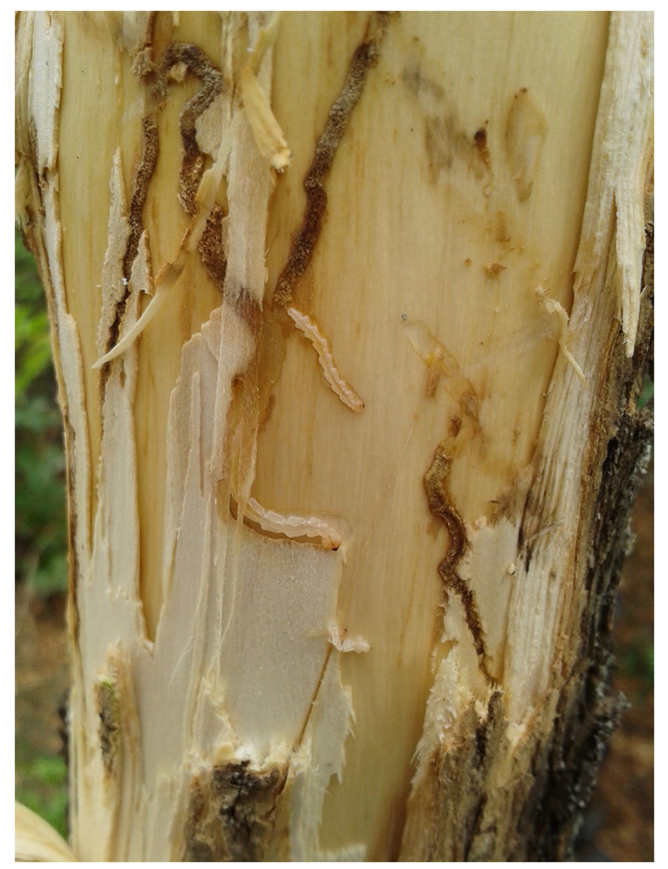

Fig. 5 Larvae and larval galleries of Agrilus planipennis in Fraxinus pennsylvanica in the Luhansk region of Ukraine in September 2019. Photo by A.N. Drogvalenko

\subsubsection{Belgorod region}

Agrilus planipennis was first detected in the Belgorod region in May 2019 in several localities close to the Voronezh region and the border of Ukraine (Baranchikov and Seraya 2019). Our surveys of ash trees in the cities of Belgorod and Staryi Oskol in summer 2019 did not reveal A. planipennis. In January 2020, larval galleries and larvae were found in the north-east of the Belgorod region (Table 2).

\subsubsection{Kaluga region}

Agrilus planipennis was first detected in the Kaluga region in Obninsk city in 2012 and in Kaluga city in 2013 (OrlovaBienkowskaja 2014a). A survey of more than 100 F. pennsylvanica trees in the city of Maloyaroslavets on 31 August 2019 revealed A. planipennis exit holes and larval galleries on at least 50 of the trees.

\subsubsection{Bryansk region}

The first survey of ash trees in the city of Bryansk was conducted in 2013 and did not reveal signs of infestation by A. planipennis (Orlova-Bienkowskaja 2014a). In 2019, A. planipennis was detected in Majskij Park in Bryansk by the National Plant Protection Organization, and an official phytoquarantine zone was declared there (Rosselkhoznadzor 2019). On 1 July 2019, we examined ash trees in other districts of Bryansk and found that F. pennsylvanica trees in M.P. Kamozin Square and on Krasnoarmejskaya, Ulyaniva, and Kharkovskaja streets were heavily infested with A. planipennis. 


\subsubsection{Surveys of $F$. excelsior in the Tulskie Zaseki Forest in the center of the pest range in European Russia}

The large broad-leaved Tulskie Zaseki Forest (65,000 ha) is situated in the Tula region in the center of the current range of A. planipennis in European Russia. Fraxinus excelsior is one of the main tree species of this forest. In 2013, A. planipennis was detected near this forest, in Tula, and Shchekino as well as in the surrounding regions of Kaluga and Orel (Straw et al. 2013; Orlova-Bienkowskaja 2014a). Fraxinus pennsylvanica trees were very common in the cities of Tula and Shchekino, and almost all of them had been infested by A. planipennis (Baranchikov et al. 2018b and observations by I.A. Zabaluev). On 19-20 June 2019, more than 500 F. excelsior trees were examined in the Tulskie Zaseki Forest in two localities: near Krapivna village and in Severno-Odoevskoe Lesnichestvo. The trees were situated both along and within the forest. No signs of infestation by A. planipennis were found, and the trees appeared to be in good health.

\subsection{Belarus}

In 2017-2019, we tried to find A. planipennis in the eastern and central regions of Belarus in the cities of Borisov, Stolbtsy, Mogilev, Orsha, Vitebsk, Minsk, Krichev, and Gomel. We did not find any signs of infestations despite $F$. pennsylvanica and $F$. excelsior being commonly planted in these cities (Table 2).

\subsection{Ukraine}

On 20-22 June 2019, ash trees in Starokozhiv Forest and field shelterbelts in its vicinity were examined (in the Markivka district of the Luhansk region of Ukraine). The forest consisted of Acer platanoides L., F. excelsior, Pyrus sp., and Quercus sp. The undergrowth and edges consisted of Acer campestre L., Acer tataricum L., Fraxinus excelsior, F. pennsylvanica, Prunus fruticosa Pallas., and P. spinosa L. The shelterbelts consisted mainly of $F$. pennsylvanica. During the examination of 250 ash trees, three $F$. pennsylvanica trees damaged by A. planipennis were detected. These trees were situated at the edge of the shelterbelts and had diameters of 7 $10 \mathrm{~cm}$. Characteristic D-shaped exit holes were situated at a height of 50-200 $\mathrm{cm}$ above the groundline. The infested trees had dieback of the upper branches, and foliage density was reduced (i.e., the trees had fewer and smaller leaves).

On 2 July 2019, we posted an early version of this manuscript on the Internet as a preprint (Orlova-Bienkowskaja et al. 2019). Immediately following the appearance of this preprint on the Internet, the National Plant Protection Organization of Ukraine conducted an official survey in the same area and did not $\operatorname{detect} A$. planipennis. Since there were no specimens or photos for confirmation, our record of A. planipennis in Ukraine was considered unreliable (EPPO 2019a).

On September 4-6, 2019, Drogvalenko visited the Markivka district in the Luhansk region of Ukraine again and repeated his survey of ash trees. He found the same three trees and more than 40 other $F$. pennsylvanica trees that were heavily infested with A. planipennis; took photos of larvae, larval galleries (Fig. 4), and exit holes; and collected more than 20 larvae of different instars, including the last (4th) instar. The coordinates of these trees, from which the larvae were collected, are as follows: $49.614991 \mathrm{~N}, 39.559743 \mathrm{E}$; $49.614160 \mathrm{~N}, 39.572402 \mathrm{E}$; and $49.597043 \mathrm{~N}, 39.561811 \mathrm{E}$ (roadside planting). The larvae were deposited in a collection in Kharkiv, Ukraine, by Drogvalenko et al. (2019). After that, the presence of $A$. planipennis was also confirmed by the Ukrainian NPPO (EPPO 2019b). On October 22, 2019, A. planipennis was found within $2 \mathrm{~km}$ radius from initial observation point outside the established quarantine zone (Meshkova 2019).

Our survey of ash trees in other localities of Ukraine (Luhansk region, Donetsk region, and Kharkiv city) did not reveal any $A$. planipennis infestations despite both $F$. pennsylvanica and $F$. excelsior being usual in these regions and occurring in both natural forests and in plantings (shelterbelts and along roads) (Table 2, Fig. 2).

\section{Discussion}

\subsection{Current borders of $A$. planipennis range in Europe}

Previously published records (Table 1) and our surveys in 2017-2020 (Table 2) indicate that by 2020, A. planipennis occurred in the Luhansk region of Ukraine and in at least 16 regions of European Russia: Belgorod, Bryansk, Kaluga, Kursk, Lipetsk, Moscow, Orel, Ryazan, Smolensk, Tambov, Tula, Tver, Vladimir, Volgograd, Voronezh, and Yaroslavl (Fig. 1). It should be noted that these results were obtained by simple surveys of ash trees without the use of pheromone traps. Usually, the signs of A. planipennis become visible only several years after the establishment of this pest in a region (Haack et al. 2015). Therefore, the real range of A. planipennis in Europe could be even more extensive.

The westernmost known A. planipennis localities are in Semirechje (Zvyagintsev et al. 2015) and Smolensk city (Baranchikov and Seraya 2018) in the Smolensk region. In the northwest, the border of the range is near Zubtsov and Tver in the Tver region. The northernmost locality is Yaroslavl. The eastern border of the range in European Russia is poorly known. The extreme localities in this direction are Yaroslavl, Petushki (Vladimir region), Vysokoe (Ryazan region), Michurinsk (Tambov region), and Volgograd. However, it is unknown if this is the true eastern 
border of the range, since few surveys were conducted further east of these localities. The most eastern and the most southern known locality was Volgograd. In the southwest, the known border crossed the Bryansk, Kursk, Belgorod, and Voronezh regions of Russia and the Luhansk region of Ukraine. In the southwest, the border of A. planipennis known range almost coincided with the Russian-Ukrainian border. Therefore, it is quite possible that $A$. planipennis will soon be found on the other side of the state border, in the Chernihiv, Sumy, and Kharkiv regions of Ukraine.

\subsection{Dynamics of the range since 2013}

The northern and northwestern borders of A. planipennis range in European Russia in 2019 were almost the same as those in 2013. The northernmost locality-Yaroslavl—is at a latitude of 57.63 $\mathrm{N}$, i.e., much further north than the northernmost locality of A. planipennis in North America (47.31 N) (Emerald Ash Borer Info 2019) and in Asia (49.42 N) (Orlova-Bienkowskaja and Volkovitsh 2018). Therefore, it is unknown whether A. planipennis can spread further north to St. Petersburg and northern Europe or if it has already reached its potential border in the north. To answer this question, an ecological model of the potential range of A. planipennis in Europe should be created, taking into account that the generation time in Moscow is 2 years (Orlova-Bienkowskaja and Bieńkowski 2016).

In the south, the situation is much worse. Agrilus planipennis is quickly spreading. It has now appeared in Ukraine and in the nearby areas of European Russia, such as the Volgograd, Bryansk, Kursk, Belgorod regions, and the south of the Voronezh region.

\subsection{Perspectives for European forestry}

The distance from Moscow to Volgograd is more than $900 \mathrm{~km}$, which is more than the distance from Moscow to Lithuania, Latvia, and Estonia. Obviously, the pest can be detected in any part of Eastern Europe. In addition, A. planipennis could soon appear in Kazakhstan, given that the distance between Volgograd and the border of Kazakhstan is approximately $150 \mathrm{~km}$.

Since there are no infested $F$. excelsior trees in the large Tulskie Zaseki Forest in European Russia, it seems that F. excelsior could be more resistant to the pest than ash species native to North America are, at least in natural forest stands. All cases of infestation of $F$. excelsior in Russia correspond to trees that grew near plantings of $F$. pennsylvanica. Fraxinus pennsylvanica is highly susceptible to A. planipennis and trees of this species are a source for the outbreak of the pest, which can also attack $F$. excelsior trees growing nearby. A similar situation was observed in China; in 1964, plantings of Fraxinus americana L. introduced from North America triggered the outbreak of A. planipennis in Harbin (Liu et al.
2003). The pest damaged both $F$. americana and native ash species in the region, but after the $F$. americana trees were cut, the outbreak ended.

Agrilus planipennis has not yet become a major forest pest in European Russia or Ukraine. It occurs in artificial plantings, such as urban plantings, along roads, railroads, and in shelterbelts. The overwhelming majority of infested and dead trees are $F$. pennsylvanica. The only ash species native to European Russia, F. excelsior, is also susceptible to A. planipennis, but there is still no evidence of the widespread mortality of this ash species in European forests. There is no doubt that A. planipennis will severely damage plantings of $F$. pennsylvanica in Europe. However, the prognosis for the future of $F$. excelsior in European forests is still uncertain.

\section{Conclusion}

In just 16 years, following the first record in Europe, A. planipennis has spread over an area of $600,000 \mathrm{~km}^{2}$ (i.e., its current range exceeds the area of Spain). The range includes 16 regions of European Russia and the Luhansk region of Ukraine. The pest is quickly spreading to the south and will undoubtedly appear in other European countries soon. No expansion of the range to the north has been detected since 2013. No case of serious A. planipennis damage to $F$. excelsior in European forests has been detected yet. Therefore, it is still unknown whether A. planipennis will become a devastating forest pest in Europe or just a pest of urban plantings. An extensive survey of the European ash (F. excelsior) in natural forests is necessary to determine the future possible impact of A. planipennis on European forests. We hope that this article will encourage experts from different European countries to study A. planipennis before this pest reaches the EU.

Acknowledgments We thank A.B. Ruchin from Mordovski Nature Reserve, L.V. Egorov from Prisurski Nature Reserve, A.N. Volodchenko from Saratov State University, A.A. Bieńkowski from Moscow State University, R.N. Ishin from Tambov State University, P.A. Zavalishin from Saint Petersburg State Forest Technical University, and V.V. Anikin and M.V. Lavrentiev from Saratov State University for the information about the surveys of ash trees in different regions of European Russia and Belarus and S.A. Bieńkowski for the preparation of the maps and photos.

Funding information This study was funded by Russian Science Foundation (grant number 16-14-10031).

Data availability All data generated or analyzed during this study are included in this published article.

\section{Compliance with ethical standards}

Conflict of interest The authors declare that they have no conflict of interest. 


\section{References}

Baranchikov YN (2013) EAB is the leading abbreviation for European forest protection in the first half of this century. In: Selikhovkin AV, Musolin DL (eds) The Kataev Memorial Readings - 7. Pests and diseases of woody plants in Russia. Proceedings of the international conference. Saint Petersburg (Russia), November, 25-27, 2013. Saint Petersburg State Forest Technical University, Saint Petersburg, pp 8-9 (in Russian)

Baranchikov YN (2018) Preparing for protection of European forests from invasive species of buprestids. Sibirskij Lesnoj Zurnal 6: 126-131 (in Russian with English abstract). https://doi.org/10. 15372/SJFS20180612

Baranchikov YN, Kurteev VV (2012) Invasive area of the emerald ash borer in Europe. Ecological and economical consequences of invasions of dendrophilous insects. Forest Institute of Siberian Branch of Russian Academy of Sciences, Krasnoyarsk, pp 91-94 (in Russian)

Baranchikov YN, Seraya LG (2018) Smolensk is occupied by Agrilus planipennis (Coleoptera: Buprestidae) ten years ago. In: Selikhovkin AV, Musolin DL (eds) The Kataev Memorial Readings -10 . Proceedings of the international conference. Saint Petersburg (Russia), October, 22-25, 2018. Saint Petersburg State Forest Technical University, Saint Petersburg, p 10 (in Russian). https://doi.org/10.21266/SPBFTU.2018.KATAEV.1

Baranchikov YN, Seraya LG (2019) The emerald ash borer on the way to Belgorod. Botanic Gardens Conserv Int Russ Div Newsl 12(35):9194 (in Russian). https://doi.org/10.25791/cbgcis.12(35).976

Baranchikov YN, Mozolevskaya EG, Yurchenko GI, Kenis M (2008) Occurrence of the emerald ash borer (Agrilus planipennis) in Russia and its potential impact on European forestry. EPPO Bull 38:233-238

Baranchikov YN, Gninenko YI, Yurchenko GI (2010) Emerald ash borer in Russia: 2009 situation update. Proc. 21st USDA Interagency research forum on invasive species. USDA Forest Service, Northern Research Station: Morgantown, WV. GTR-NRSP-75, pp 66-67

Baranchikov YN, Seraya LG, Grinash MN (2014) All European ash species are susceptible to emerald ash borer Agrilus planipennis Fairmaire (Coleoptera: Buprestidae) - a Far Eastern invader. Sib J Forest Sci 6:80-85

Baranchikov YN, Demidko DA, Seraya LG (2018a) A quarter-century of emerald ash borer in Europe. In: Preparing Europe for invasion by the beetles emerald ash borer and bronze birch borer, two major treekilling pests October 1-4, 2018, Vienna. Austrian Research Centre for Forests (BFW), Abstracts, p 9

Baranchikov YN, Demidko DA, Seraya LG (2018b) Deep in the rear of the invasion: Agrilus planipennis (Coleoptera: Buprestidae) in Tula. In: Selikhovkin AV, Musolin DL (eds) The Kataev Memorial Readings -10 . Proceedings of the International Conference. Saint Petersburg (Russia), October, 22-25, vol 2018. Saint Petersburg State Forest Technical University, Saint Petersburg, pp 8-9 (in Russian). https://doi.org/10.21266/SPBFTU.2018.KATAEV.1

Chamorro ML, Volkovitsh MG, Poland TM, Haack RA, Lingafelter SW (2012) Preimaginal stages of the emerald ash borer, Agrilus planipennis Fairmaire (Coleoptera: Buprestidae): an invasive species of ash trees (Fraxinus). PLoS One 7(3):e33185. https://doi.org/ 10.1371/journal.pone.0033185

Drogvalenko AN, Orlova-Bienkowskaja MJ, Bieńkowski AO (2019) Record of the emerald ash borer (Agrilus planipennis) in Ukraine is confirmed. Insects 10:338. https://doi.org/10.3390/ insects 10100338

Emereld Ash Borer Info (2019) http://www.emeraldashborer.info. Accessed 28 June 2019

EPPO (2019a) Global database. Agrilus planipennis does not occur in Ukraine EPPO Reporting Service (2019/156) Available online: https://gdeppoint/reporting/article-6586 Accessed 18 December 2019

EPPO (2019b) Global database. Presence of Agrilus planipennis confirmed in Ukraine. EPPO reporting service (2019/202) available online: https://gd.eppo.int/reporting/article-6632 Accessed 18 Dec 2019

EU (2019) Commission Delegated Regulation (EU) 2019/1702 of 1 August 2019 supplementing regulation (EU) 2016/2031 of the European Parliament and of the council by establishing the list of priority pests. OJ L 260:8-10 http://data.europa.eu/eli/reg_del/2019/ 1702/oj. Accessed 18 Dec 2019

Haack RA, Baranchikov Y, Bauer LS, Poland TM (2015) Emerald ash borer biology and invasion history. In: Van Driesche RG, Reardon RC (eds) Biology and control of emerald ash borer. FHTET 2014 09. U.S. Department of Agriculture, Forest Service, Forest health technology Enterprise team, Morgantown, pp 1-13

Herms DA (2015) Host range and host resistance. In: Van Driesche RG, Reardon RC (eds) Biology and control of emerald ash borer. FHTET 2014-09. U.S. Department of Agriculture, Forest Service, Forest health technology Enterprise team, Morgantown, pp 65-73

Herms DA, McCullough DG (2014) Emerald ash borer invasion of North America: history, biology, ecology, impacts, and management. Annu Rev Entomol 59:13-30. https://doi.org/10.1146/annurevento-011613-162051

Izhevskii SS, Mozolevskaya EG (2010) Agrilus planipennis Fairmaire in Moscow ash trees. Russ J Biol Invasions 1(3):153-155

Liu HP, Bauer LS, Gao R, Zhao T, Petrice TR, Haack RA (2003) Exploratory survey for emerald ash borer, Agrilus planipennis (Coleoptera: Buprestidae) and its natural enemies in China. Great Lakes Entomol 36:191-204

Meshkova VL (2019) Emerald ash borer - newly arriving to our territories. Nauka 6:8-11 (in Ukrainian)

Mozolevskaya EG (2012) Present important species of dendrophilous insects in urban green plantations of Moscow. In: Ekologicheskie i ekonomicheskie posledstviya invaziidendrofil'nykh nasekomykh (ecological and economic consequences of invasion of Dendrophilous insects). Inst. Lesa Sib. Otd. Ross. Akad. Nauk, Krasnoyarsk, pp. 23-24 (in Russian)

Orlova-Bienkowskaja MJ (2014a) Ashes in Europe are in danger: the invasive range of Agrilus planipennis in European Russia is expanding. Biol Invasions 16(7):1345-1349. https://doi.org/10. 1007/s10530-013-0579-8

Orlova-Bienkowskaja MJ (2014b) European range of the emerald ash borer Agrilus planipennis (Coleoptera: Buprestidae) is expanding: the pest destroys ashes in the northwest of Moscow Oblast and in part of Tver Oblast. Russ J Biol Invasions (Springer) 5(1):32-37. https://doi.org/10.1134/S2075111714010081

Orlova-Bienkowskaja MJ, Belokobylskij SA (2014) Discovery of the first European parasitoid of the emerald ash borer Agrilus planipennis (Coleoptera: Buprestidae). Eur J Entomol 111(4):594 596

Orlova-Bienkowskaja MJ, Bieńkowski AO (2016) The life cycle of the emerald ash borer Agrilus planipennis in European Russia and comparisons with its life cycles in Asia and North America. Agric For Entomol 18(2):182-188. https://doi.org/10.1111/afe.12140

Orlova-Bienkowskaja MJ, Bieńkowski AO (2018a) Modeling longdistance dispersal of emerald ash borer in European Russia and prognosis of spread of this pest to neighboring countries within next 5 years. Ecol Evol 8:9295-9304. https://doi.org/10.1002/ece3.4437

Orlova-Bienkowskaja MJ, Bieńkowski AO (2018b) To EAB or not to EAB? It is doubtful that Agrilus planipennis will become a devastating forest pest in Europe in the nearest future. In: Preparing Europe for invasion by the beetles emerald ash borer and bronze birch borer, two major tree-killing pests, October 1-4, 2018. Austrian research Centre for Forests (BFW), Vienna, Abstracts, p. 
$31 \mathrm{https} / / / \mathrm{bfw} . a c . a t / \mathrm{cms} \_s t a m m / 050 / \mathrm{PDF} /$ prepsys_abstracts.pdf. Accessed 18 Dec 2019

Orlova-Bienkowskaja MJ, Volkovitsh MG (2014) Range expansion of Agrilus convexicollis in European Russia expedited by the invasion of emerald ash borer, Agrilus planipennis (Coleoptera: Buprestidae). Biol Invasions 17(2):537-544. https://doi.org/10.1007/s10530-0140762-6

Orlova-Bienkowskaja MJ, Volkovitsh MG (2018) Are native ranges of the most destructive invasive pests well known? A case study of the native range of the emerald ash borer, Agrilus planipennis (Coleoptera: Buprestidae). Biol Invasions 20(5):1275-1286. https://doi.org/10.1007/s10530-017-1626-7

Orlova-Bienkowskaja MJ, Drogvalenko AN, Zabaluev IA, Sazhnev AS, Peregudova EY, Mazurov SG, Komarov EV, Bieńkowski AO (2019) Bad and good news for ash trees in Europe: alien pest Agrilus planipennis has spread to the Ukraine and the south of European Russia, but does not kill Fraxinus excelsior in the forests. BioRxiv [Preprint]. https://doi.org/10.1101/689240

Peregudova EY (2016) The first records of buprestid beetle Agrilus planipennis in Tver city and Agrilus convexicollis in Tver Oblast. In: Musolin DL, Selikhovkin AV (eds) Dendrobiont invertebrates and fungi and their role in forest ecosystems. Proceedings of the international conference. Saint Petersburg (Russia), November 2325, 2016. Saint Petersburg State Forest Technical University, Saint Petersburg, $\mathrm{p} 82$ (in Russian)

Peregudova EY (2019) The emerald ash borer focus in Tver City, in the north-western border of the invasive range. Russ J Biol Invasions 2: $80-86$

Rosselkhoznadzor (2014) Russian National Plant Protection Organization. Rosselkhoznadzor has confirmed the information about detection of the Emerald Ash Borer in Livny http://www. fsvps.ru/fsvps/print/press/68279.html (in Russian). Accessed 26 June 2019

Rosselkhoznadzor (2019) Russian National Plant Protection Organization. Open Data Russia https://data.gov.ru/opendata/ 7708523530-carantinzone (in Russian). Accessed 27 September 2019

Showalter DN, Saville RJ, Orton ES, Buggs RJA, Bonello P, Brown JKM (2019) Resistance of European ash (Fraxinus excelsior) saplings to larval feeding by the emerald ash borer (Agrilus planipennis). Plants People Planet 00:1-6. https://doi.org/10.1002/ppp3.10077

Straw NA, Williams DT, Kulinich OA, Gninenko YI (2013) Distribution, impact and rate of spread of emerald ash borer Agrilus planipennis (Coleoptera: Buprestidae) in the Moscow region of Russia. Forestry 86:515-522. https://doi.org/10.1093/forestry/cpt031

Vesti Volgograd (2018) https://www.youtube.com/watch?v= kV81He1Ddc8 (in Russian). Accessed 26 June 2019

Volkovitsh MG, Orlova-Bienkowskaja MJ, Kovalev AV, Bieńkowski AO (2019) An illustrated guide to distinguish emerald ash borer (Agrilus planipennis) from its congeners in Europe. Forestry 1-10. https:// doi.org/10.1093/forestry/cpz024

Zvyagintsev VB, Baranov OY, Panteleev SV (2015) The prevalence of necrosis of ash branches caused by the invasive pathogen Hymenoscyphus fraxineus Baral et al. in the Moscow Oblast and along the highway M1. Current Mycology in Russia 5(1), chapter 10: 413-414 (in Russian). https://doi.org/10.14427/cmr.2015.v.10

Publisher's note Springer Nature remains neutral with regard to jurisdictional claims in published maps and institutional affiliations.

\section{Affiliations}

\section{Marina J. Orlova-Bienkowskaja ${ }^{1}$ (D) - Alexander N. Drogvalenko ${ }^{2} \cdot \|_{\text {llya A. Zabaluev }}{ }^{1}$ - Alexey S. Sazhnev ${ }^{3}$. Elena Y. Peregudova ${ }^{4}$. Sergey G. Mazurov ${ }^{5}$. Evgenij V. Komarov ${ }^{6} \cdot$ Vitalij V. Struchaev $^{7} \cdot$ Vladimir V. Martynov ${ }^{8}$. Tatyana V. Nikulina ${ }^{8} \cdot$ Andrzej O. Bieńkowski $^{1}$}

1 A.N. Severtsov Institute of Ecology and Evolution, Russian Academy of Sciences, 33 Leninskiy Prospect, Moscow 119071, Russia

2 V.N. Karazin Kharkiv National University, 4 Svobody Square, Kharkiv 61022, Ukraine

3 Papanin Institute for Biology of Inland Waters, Russian Academy of Sciences, Borok, Nekouz District 152742, Yaroslavl Region, Russia

4 Saint Petersburg State Forest Technical University, Institutskiy per., 5, Saint Petersburg 194021, Russia
5 Middle School of General education, Leski, Krasnoe District 399675, Lipetsk Region, Russia

6 All-Russian Scientific Research Institute of Irrigated Agriculture, Timiryazev str., 9, Volgograd 400002, Russia

7 Agrobiotekhnologia, Kolkhoznaya Street 3/1, Churaevo, Shebekino District 309251, Belgorod Region, Russia

8 Public Institution "Donetsk Botanical Garden”, 110 Illicha Prospect, Donetsk 283059, Donetsk People's Republic, Ukraine 